\title{
Pollen flow and effects of population structure on selfing rates and female and male reproductive success in fragmented Magnolia stellata populations
}

\author{
Suzuki Setsuko ${ }^{1 *}$, Teruyoshi Nagamitsu ${ }^{1}$ and Nobuhiro Tomaru ${ }^{2}$
}

\begin{abstract}
Background: Fragmentation of plant populations may affect mating patterns and female and male reproductive success. To improve understanding of fragmentation effects on plant reproduction, we investigated the pollen flow patterns in six adjacent local populations of Magnolia stellata, an insect-pollinated, threatened tree species in Japan, and assessed effects of maternal plant (genet) size, local genet density, population size and neighboring population size on female reproductive success (seed production rates), and effects of mating distance, paternal genet size, population size and separation of populations on male reproductive success.
\end{abstract}

Results: The seed production rate, i.e. the proportion of ovules that successfully turned into seeds, varied between 1.0 and 6.5\%, and increased with increasing population size and neighboring population size, and with decreasing maternal genet size and local genet density. The selfing rate varied between 3.6 and 28.9\%, and increased with increasing maternal genet size and with declining local genet density. Male reproductive success increased with increasing paternal genet size, and decreased with increasing mating distance and separation of population. Pollen flow between the populations was low (6.1\%) and highly leptocurtic.

Conclusions: Our results indicate that habitat fragmentation, separation and reduced size of populations, affected mating patterns and reproductive success of M. stellata. Local competition for pollinators and plant display size were likely to alter the reproductive success.

Keywords: Conservation, Fragmentation, Gene flow, Geitonogamy, Insect pollination, Landscape, Magnoliaceae, Paternity analysis, Pollen dispersal, Seed production

\section{Background}

Fragmentation disrupts continuous populations, resulting in smaller, separated populations. The fragmentation of plant populations may decrease seed production and outcrossing rates due to limitations of mates and pollinators in the remaining, fragmented populations, potentially reducing reproductive success $[1,2]$. Thus, the reproductive success of parent plants and fitness of their offspring may be reduced [3-6]. Fragmentation may also lead to reductions in the frequency of gene flow among populations and

\footnotetext{
*Correspondence: setsukos@affrc.go.jp

1 Department of Forest Genetics, Forestry and Forest Products Research Institute, Tsukuba, Ibaraki 305-8687, Japan

Full list of author information is available at the end of the article
}

genetic variation within populations due to genetic drift [7]. Among plant taxa, woody plant species are relatively resistant to reductions in reproductive success and genetic variation due to habitat fragmentation owing to the longevity of individuals, relatively high local genetic diversity and extensive gene flow $[8,9]$. However, recent meta-analyses suggest that fragmentation is likely to reduce the genetic variation of woody plant species as much as that of herbaceous species [10], and to affect reproductive success of trees as much as that of other life forms [7].

It is especially difficult to predict the effects of population fragmentation on mating patterns and seed production of animal-pollinated trees, since the abundance and behavior of pollinators may change as the size and isolation of their

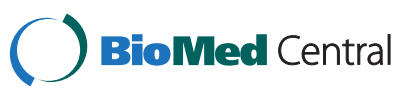


populations change $[11,12]$. Reductions in the size of tree populations are expected to decrease the abundance of resident pollinators and the attraction of pollinators migrating between populations [13]. Higher local densities of flowering trees may attract disproportionately more pollinators, resulting in higher pollination frequencies [14]. On the other hand, increases in local tree density may increase local competition for pollinators, as observed in large populations of insect-pollinated shrubs [15]. At the individual level, the size of trees, which is related to floral display size and resource availability, is also likely to affect pollination rates and seed production.

Particularly in mixed-mating trees, the selfing rate is likely to increase as the availability of mates and pollinators decreases in small, fragmented populations $[2,7,16]$. Geitonogamous selfing (self-pollination between flowers within individuals), which is prevalent in trees, also tends to increase in large trees that produce abundant flowers and at sites with low local floral density and limited mate availability $[17,18]$. Selfed offspring of most outcrossing trees with high degrees of inbreeding depression $[19,20]$ have low survival and growth rates, and consequently low fitness. Population fragmentation is also likely to alter patterns of pollen-mediated gene flow (pollen flow). Forest fragmentation can either impede or facilitate pollen flow between tree populations [21-23], because landscape elements between the remaining forests may have either positive or negative effects on pollinator transfer [24]. Rather than hindering pollen flow, fragmentation and reductions in tree density frequently result in increased pollination distances [25]. The rates of immigrant pollen flow from outside often increases in fragmented populations, except in extremely isolated populations [22,25-27]. Furthermore, not only immigration but also emigration of pollen, i.e. pollen donation from one population to another, may play important roles in the maintenance of genetic connectivity among populations [28]. Hence, measuring both the direction and frequency of pollen flow between populations is necessary to evaluate effects of population fragmentation on mating patterns.

An explicit method to clarify the direction of pollen flow between populations, and quantify the composition of contemporary pollen flow, is paternity analysis of seeds collected from known mothers to determine the origin of pollen that fertilized seeds. It was first applied by Adams and Birkes $[29,30]$ in attempts to simultaneously estimate pollen flow and factors related to male fertility, such as distances to mother trees and the degree of floral synchrony. This approach was extended by Burczyk et al. [31], who constructed a neighborhood model to utilize genetic marker data from diploid offspring, and Klein et al. [32], who proposed a new spatially explicit model to estimate jointly the variance of male fecundity and pollen dispersal kernels. However, in fragmented tree populations, mating patterns may depend not only on individual properties, such as the tree size and inter-tree distance, but also population properties, such as the size and separation of populations. Hence, models including factors at both individual and population levels are required to estimate determinants of pollen flow patterns and male reproductive success.

In this study, we assessed pollen flow and assessed selfing rates and female and male reproductive success in six fragmented populations of a threatened tree species, Magnolia stellata. This species produces insectpollinated flowers, it has a mixed mating system with substantial amounts of selfed seeds, and its seed production is often pollen-limited $[33,34]$. Thus, the species is suitable for investigating effects of population fragmentation on selfing rates and reproductive success. First we assessed seed production rates in the studied populations to obtain estimates of female reproductive success, and then conducted paternity analysis of seeds collected from the trees. Next, we examined the selfing rates, from the assigned paternity data. Then, we estimated male reproductive success and pollen dispersal from the results of the paternity analysis. Finally, we evaluated the effects of genet size, local genet density, population size and neighboring population size as a indicator of population isolation on female reproductive success and selfing rates, and the effects of mating distance, genet and population size and geographical separation of the populations on male reproductive success in the populations.

\section{Methods}

\section{Study species}

Magnolia stellata Maxim. [35] (synonym, M. tomentosa Thunb.; [36]) is a deciduous tree of the Magnoliaceae. The species is endemic to the area around the Ise Bay of Central Japan and is now considered near threatened (NT) in the Japanese Red List [37]. Habitats of this species are swampy places, such as streamsides and marshes, in the uppermost parts of valleys [38]. The species reaches heights up to $10 \mathrm{~m}$. It blossoms in early spring, forming protogynous, insect-pollinated flowers. The mean flowering duration for an individual tree is 13.2 days, and the mean total flowering duration of the individual flower and the durations of the female, transitionary and male phases of individual flowers are reportedly 10.3, 4.1, 0.7 and 5.5 day, respectively [39]. The main flower visitors are small beetles [40], as in many other Magnolia species [41-44]. Each flower can produce one fruit. The fruits have ca. 30 to 40 carpels, and each carpel usually has two ovules and can produce at most two red seeds. Seeds are dispersed by both gravity [45] and birds, such as the brown-eared bulbul (Hypsipetes amaurotis) and Japanese thrush (Turdus cardis) (T. Kimura et al. unpublished data). 


\section{Study area}

The research site is located in the Kaisho Forest, near Nagoya City, Aichi Prefecture, Japan (35 11' 25" N, $137^{\circ}$ $\left.06^{\prime} 55^{\prime \prime} \mathrm{E}\right)$. This area supports a secondary forest that is mainly composed of Pinus densiflora, Ilex pedunculosa, Quercus serrata and Clethra barvinervis [46]. The potential natural vegetation of this area is evergreen broad-leaved forest, but the forest is now mainly dominated by deciduous trees because people utilized the trees for fuel wood for a long time in the past. However, since people stopped using the wood for fuel, evergreen broad-leaved trees have been increasing via secondary succession.

We define 'a population' here as a group of genets in the uppermost part of one of the valleys in the area, each of which is separated from adjacent populations by ridges (Figure 1). Eight M. stellata populations (designated $\mathrm{Y}, \mathrm{T}, \mathrm{A}, \mathrm{B}, \mathrm{C}, \mathrm{D}, \mathrm{E}$ and $\mathrm{F}$ ) in the southwestern part of the Kaisho Forest were surveyed. The locations and designations of these populations are shown in Figure 1. No other population is present in or around the study area and the nearest population outside the study area is about $1 \mathrm{~km}$ north of Population $\mathrm{C}$.

\section{Determination of adult genets}

Since $M$. stellata genets usually consist of several ramets, due to sprouting and layering [45], different genets were distinguished in previous studies based on the connections between ramets above the ground and multilocus nuclear microsatellite (nSSR) genotypes $[38,45]$. In one of the previous studies we also surveyed all genets that flowered at least once from 2002 to 2004 (defined as adult genets) in the eight populations, and recorded the spatial coordinates and diameter at breast height $(\mathrm{DBH})$ of the largest stem of each adult genet in 2007 [39].

\section{Measures of female reproductive success}

In March 2005, we selected three to 14 genets ( 8.3 on average and 50 in total) from six populations (Y, T, A, B, C and F) and marked 11 to 96 individual flowers (33 on average and 1648 in total) of each genet (Table 1). In August 2005, we sampled mature fruits that developed from the marked flowers. The number of ovules in the marked flowers of each selected genet was estimated from the number of carpels in sampled fruits of the genet, assuming that flowers and fruits had equal numbers of carpels, and that

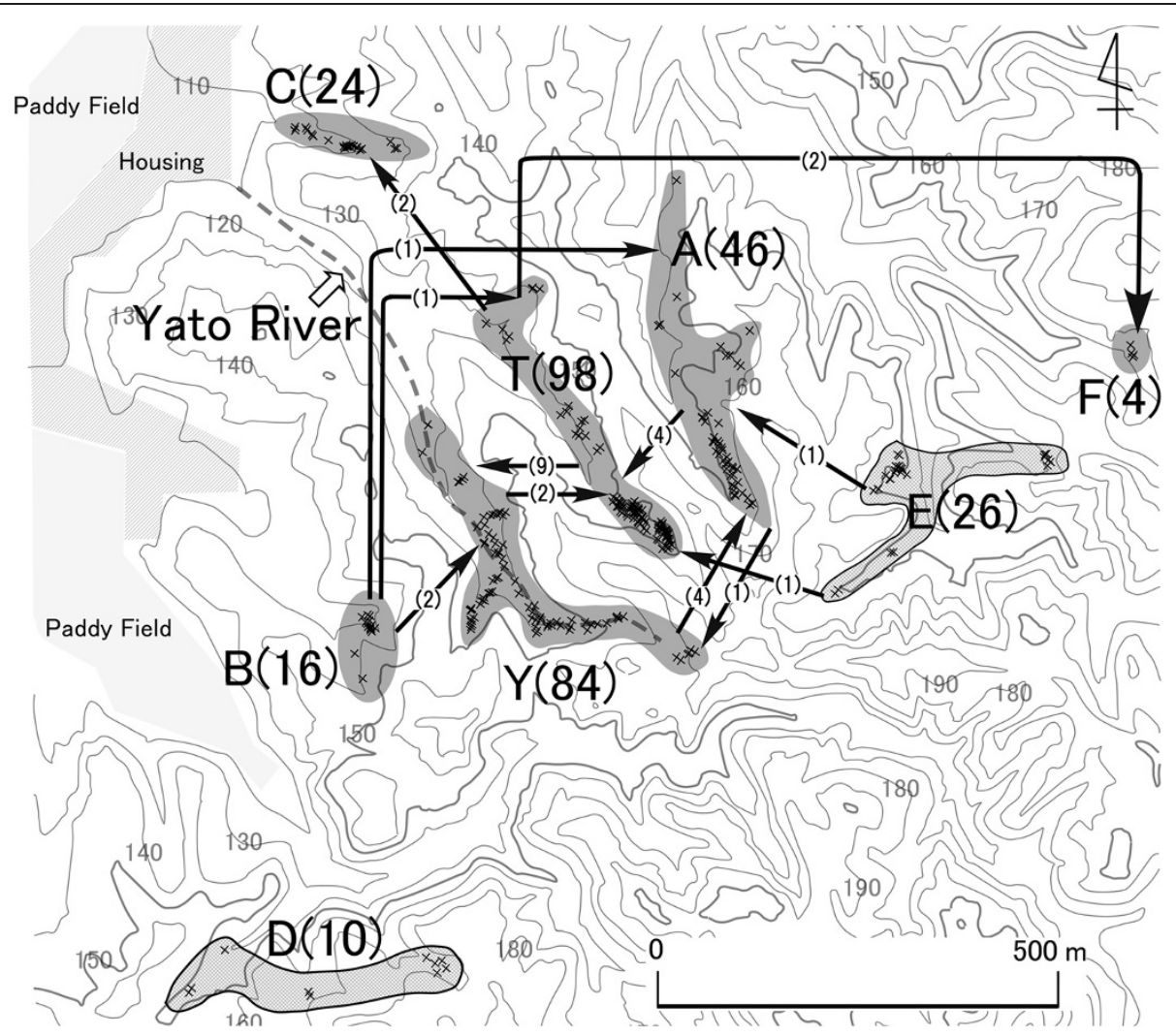

Figure 1 Spatial distribution of Magnolia stellata populations and genets examined in this study. The letters and numbers in parenthesis indicate the designations of populations and numbers of adult genets (i.e. population size), respectively. Crosses indicate the locations of genets. Gray $(Y, T, A, B, C, F)$ and meshed areas $(D, E)$ indicate locations of populations in which seeds were and were not sampled, respectively. Arrows represent pollen flow and the numbers by the arrows indicate the numbers of pollen migration events. 
Table 1 Seed production rate, results of paternity analysis, immigration and selfing rates per tree per population

\begin{tabular}{|c|c|c|c|c|c|c|c|c|c|c|}
\hline \multirow{2}{*}{$\begin{array}{l}\begin{array}{l}\text { Population } \\
\text { (population size) }\end{array} \\
Y(84)\end{array}$} & \multirow{2}{*}{$\begin{array}{l}\begin{array}{l}\text { Seed } \\
\text { parents }\end{array} \\
\text { Y4 }\end{array}$} & \multirow{2}{*}{$\begin{array}{l}\begin{array}{l}\text { DBH } \\
(\mathrm{cm})\end{array} \\
5.4\end{array}$} & \multirow{2}{*}{$\begin{array}{l}\text { No. flower } \\
\text { marked }\end{array}$} & \multirow{2}{*}{$\begin{array}{l}\text { Seed production } \\
\text { rate (\%) } \\
-\end{array}$} & \multirow{2}{*}{$\begin{array}{l}\begin{array}{l}\text { No. samples for } \\
\text { paternity analysis }\end{array} \\
4\end{array}$} & \multicolumn{2}{|c|}{$\begin{array}{l}\text { Immigration } \\
\text { rate by } \\
\text { pollen }(\%)\end{array}$} & \multirow{2}{*}{$\begin{array}{l}\text { Pollen source } \\
\text { population }\end{array}$} & \multicolumn{2}{|c|}{$\begin{array}{l}\text { Selfing } \\
\text { rate }(\%)\end{array}$} \\
\hline & & & & & & 0.0 & (0) & & 0.0 & (0) \\
\hline & Y5 & 6.0 & - & - & 17 & 11.8 & (2) & $\mathrm{T}(2)$ & 0.0 & $(0)$ \\
\hline & Y20 & 6.3 & - & - & 19 & 0.0 & (0) & - & 0.0 & $(0)$ \\
\hline & Y56 & 6.0 & 46 & 5.2 & 6 & 0.0 & (0) & - & 100.0 & $(6)$ \\
\hline & Y83 & 6.2 & 73 & 0.6 & 13 & 7.7 & (1) & $\mathrm{T}(1)$ & 0.0 & $(0)$ \\
\hline & Y90 & 9.0 & - & - & 6 & 0.0 & (0) & - & 83.3 & (5) \\
\hline & Y91 & 9.2 & - & - & 17 & 5.9 & (1) & $B(1)$ & 0.0 & (0) \\
\hline & Y98 & 5.3 & - & - & 11 & 0.0 & (0) & - & 0.0 & (0) \\
\hline & Y129 & 4.4 & 20 & 1.6 & 3 & 0.0 & (0) & - & 33.3 & $(1)$ \\
\hline & Y136 & 1.4 & - & - & 3 & 66.7 & (2) & $A(1), B(1)$ & 0.0 & (0) \\
\hline & Y137 & 3.2 & 90 & 3.2 & 11 & 27.3 & (3) & $\mathrm{T}(3)$ & 27.3 & (3) \\
\hline & Y141 & 2.8 & 12 & 7.6 & 15 & 0.0 & (0) & - & 0.0 & $(0)$ \\
\hline & Y145 & 5.7 & 96 & 6.0 & 12 & 16.7 & (2) & $\mathrm{T}(2)$ & 41.7 & (5) \\
\hline & Y150 & 3.7 & 17 & 4.5 & 17 & 5.9 & (1) & $\mathrm{T}(1)$ & 5.9 & (1) \\
\hline & Y158 & 5.7 & 54 & 7.2 & 1 & 0.0 & (0) & - & 100.0 & (1) \\
\hline & Y160 & 6.4 & - & - & 9 & 0.0 & (0) & - & 66.7 & (6) \\
\hline & Y161 & 3.8 & 29 & 4.0 & 3 & 0.0 & (0) & - & 33.3 & $(1)$ \\
\hline & Y175 & 4.6 & 18 & 3.5 & - & - & - & - & & \\
\hline Mean (Total) & & 5.28 & $45.50(455)$ & 4.33 & $9.82(167)$ & 8.34 & $(12)$ & $\mathrm{T}(9), \mathrm{A}(1), \mathrm{B}(2)$ & 28.91 & (29) \\
\hline \multirow[t]{15}{*}{$\mathrm{T}(98)$} & $\mathrm{T} 2$ & 5.7 & - & - & 14 & 14.3 & (2) & $Y(1), A(1)$ & 0.0 & $(0)$ \\
\hline & $\mathrm{T} 17$ & 7.7 & 71 & 0.7 & 6 & 0.0 & (0) & - & 0.0 & (0) \\
\hline & T24 & 3.8 & 25 & 4.7 & 2 & 0.0 & (0) & - & 0.0 & (0) \\
\hline & T25 & 3.9 & 39 & 1.0 & 7 & 0.0 & (0) & - & 0.0 & $(0)$ \\
\hline & T26 & 5.3 & 22 & 4.4 & 8 & 0.0 & (0) & - & 0.0 & (0) \\
\hline & $\mathrm{T} 27$ & 3.7 & 35 & 10.1 & 15 & 0.0 & (0) & - & 0.0 & (0) \\
\hline & T29 & 4.1 & 42 & 6.4 & 6 & 16.7 & (1) & $A(1)$ & 0.0 & $(0)$ \\
\hline & T52 & 2.5 & 42 & 4.6 & 25 & 0.0 & (0) & - & 0.0 & (0) \\
\hline & T53 & 2.8 & 35 & 2.9 & 16 & 6.3 & (1) & A (1) & 6.3 & (1) \\
\hline & T54 & 2.5 & 38 & 2.2 & 8 & 12.5 & (1) & $A(1)$ & 25.0 & (2) \\
\hline & T77 & 3.7 & 14 & 0.0 & - & - & - & - & - & - \\
\hline & T91 & 5.1 & 32 & 26.0 & 1 & 0.0 & (0) & - & 0.0 & (0) \\
\hline & T92 & 6.5 & 33 & 3.4 & 10 & 20.0 & (2) & $Y(1), B(1)$ & 50.0 & (5) \\
\hline & T99 & 2.4 & 22 & 3.0 & 10 & 10.0 & (1) & $E(1)$ & 0.0 & (0) \\
\hline & $\mathrm{T} 100$ & 3.7 & 63 & 5.4 & 9 & 0.0 & (0) & - & 0.0 & $(0)$ \\
\hline Mean (Total) & & 4.22 & $36.64(513)$ & 5.35 & 9.79 (137) & 5.69 & (8) & $Y(2), A(4), B(1), E(1)$ & 5.80 & (8) \\
\hline \multirow[t]{7}{*}{ A (46) } & $\mathrm{A} 1$ & 5.9 & 32 & 1.2 & 1 & 0.0 & (0) & - & 0.0 & $(0)$ \\
\hline & $\mathrm{A} 2$ & 7.5 & 18 & 5.5 & 4 & 0.0 & (0) & - & 25.0 & $(1)$ \\
\hline & A3 & 10.4 & 22 & 1.4 & 2 & 50.0 & (1) & $Y(1)$ & 0.0 & $(0)$ \\
\hline & $\mathrm{A} 18$ & 4.0 & 18 & 7.4 & 9 & 11.1 & (1) & $Y(1)$ & 0.0 & $(0)$ \\
\hline & A22 & 7.7 & 21 & 4.6 & 11 & 9.1 & (1) & $B(1)$ & 0.0 & (0) \\
\hline & A24 & 6.7 & 17 & 10.7 & 18 & 5.6 & (1) & $Y(1)$ & 0.0 & (0) \\
\hline & A25 & 8.4 & 20 & 14.7 & 22 & 9.1 & (2) & $Y(1), E(1)$ & 0.0 & (0) \\
\hline
\end{tabular}


Table 1 Seed production rate, results of paternity analysis, immigration and selfing rates per tree per population (Continued)

\begin{tabular}{|c|c|c|c|c|c|c|c|c|c|c|}
\hline Mean (Total) & & 7.22 & $21.14(148)$ & 6.50 & $9.57(67)$ & 12.12 & (6) & $Y(4), B(1), E(1)$ & 3.57 & $(1)$ \\
\hline & B2 & 5.0 & 46 & 4.7 & 9 & 0.0 & (0) & - & 0.0 & $(0)$ \\
\hline & B9 & 5.0 & 71 & 0.3 & - & - & - & - & - & - \\
\hline & B14 & 5.0 & 24 & 1.0 & 11 & 0.0 & (0) & - & 18.2 & $(2)$ \\
\hline & B18 & 5.9 & 42 & 0.8 & 6 & 0.0 & (0) & - & 33.3 & (2) \\
\hline & B31 & 3.8 & 18 & 0.2 & 4 & 0.0 & (0) & - & 50.0 & $(2)$ \\
\hline & B32 & 4.8 & 16 & 0.0 & - & 0.0 & (0) & - & - & - \\
\hline & B33 & 5.5 & 21 & 0.0 & - & - & - & - & - & - \\
\hline & B35 & 3.1 & 11 & 0.0 & - & - & - & - & - & - \\
\hline & B41 & 5.8 & 22 & 1.7 & - & - & - & - & - & - \\
\hline Mean (Total) & & 4.87 & $30.11(271)$ & 0.98 & $7.50(30)$ & 0.00 & $(0)$ & - & 25.38 & (6) \\
\hline \multirow[t]{7}{*}{$C(24)$} & $\mathrm{C} 1$ & 13.0 & 30 & 0.3 & 13 & 7.7 & (1) & $\mathrm{T}(1)$ & 38.5 & (5) \\
\hline & C21 & 7.1 & 25 & 5.4 & 10 & 10.0 & (1) & $\mathrm{T}(1)$ & 20.0 & $(2)$ \\
\hline & $\mathrm{C} 25$ & 7.3 & 19 & 5.0 & 2 & 0.0 & (0) & - & 0.0 & (0) \\
\hline & C28 & 4.4 & 17 & 6.3 & 21 & 0.0 & (0) & - & 0.0 & (0) \\
\hline & C34 & 8.2 & 13 & 13.8 & 19 & 0.0 & (0) & - & 15.8 & (3) \\
\hline & C36 & 6.8 & 14 & 2.4 & 8 & 0.0 & (0) & - & 12.5 & $(1)$ \\
\hline & C43 & 2.6 & 12 & 3.3 & 10 & 0.0 & (0) & - & 10.0 & (1) \\
\hline Mean (Total) & & 7.04 & $18.57(130)$ & 5.21 & $11.86(83)$ & 2.53 & (2) & $\mathrm{T}(2)$ & 13.82 & (12) \\
\hline \multirow[t]{3}{*}{$F(4)$} & F1 & 8.4 & 23 & 0.4 & 2 & 0.0 & (0) & - & 0.0 & (0) \\
\hline & F2 & 8.4 & 23 & 0.1 & 2 & 0.0 & (0) & - & 50.0 & $(1)$ \\
\hline & F4 & 5.4 & 22 & 2.5 & 5 & 40.0 & (2) & $\mathrm{T}(2)$ & 0.0 & (0) \\
\hline Mean (Total) & & 7.42 & $22.67(68)$ & 1.03 & $3.00(9)$ & 13.33 & (2) & $\mathrm{T}(2)$ & 16.67 & (1) \\
\hline
\end{tabular}

each carpel had two ovules [numbers of ovules in flowers = numbers of carpels in fruits $\times 2$ ]. The fruit set percentages [(the number of sampled fruits from each genet / the number of marked flowers of each genet) $\times 100$ ], and seed set [(the total number of filled seeds in sampled fruits of each genet/ the total number of ovules in marked flowers of each genet) $\times 100$ ] were calculated for every selected genet. As a measure of female reproductive success, the percentage of ovules that developed into filled seeds (seed production rate $=$ fruit set $\times$ seed set $\times 100)$ was calculated for every selected genet.

\section{Sampling and germination test for paternity assignment}

To increase the number of samples for paternity analysis, we also sampled fruits from nine additional genets that we did not survey for female reproductive success (eight in Population $\mathrm{Y}$ and one in $\mathrm{T}$ ). The fleshy pulp of seeds was removed from the sampled fruits, and the seeds were stored in water at $5^{\circ} \mathrm{C}$ for 48 weeks. Then, 30 seeds from each genet (or all seeds from genets yielding less than 30 seeds) were sown on damp filter paper. The seeds were then placed in an incubator under diurnal temperature cycles of $12 \mathrm{~h}$ at $5^{\circ} \mathrm{C}$ and $12 \mathrm{~h}$ at $25^{\circ} \mathrm{C}$ for about six months to induce germination. The numbers of seedlings that had germinated at the end of this time ranged from 0 to 25 per genet, nine to 167 per population, and 493 seedlings in total were obtained (Table 1).

\section{DNA extraction and microsatellite genotyping}

Genomic DNA was extracted from leaves of adult genets and seedlings (hereafter referred to as offspring) using a modified CTAB (Cetyltrimethylammonium bromide) method [47] with further minor modifications. Genotypes of the 493 offspring were determined using 10 SSR markers, namely M6D8 developed for M. obovata [48], and nine previously developed for $M$. stellata: stm0148, stm0184, stm0191, stm0222, stm0223, stm0251, stm0334, stm0353 and stm0423 [49]. Genotypes at the same loci of all the 306 adult genets in the eight populations had already been determined in a previous study [38].

\section{Paternity assignment}

High levels of genetic diversity $\left(H_{\mathrm{E}}=0.773 \pm 0.019\right)$ have been observed in the adult genets of all the populations [38]. Based on fixation indices $\left(F_{\text {IS }}\right)$, no significant deviation from Hardy-Weinberg equilibrium was found at any loci in any populations. No significant linkage disequilibrium between loci was observed for any population, except at one 
pair of loci in one population. Therefore, the loci seemed to be independent and had few null alleles, and the exclusion probability for the second parent was 0.99992. Detailed summaries of the data pertaining to these findings are available in Setsuko et al. [38].

Parentage analyses were performed based on the multilocus SSR genotypes of the offspring and candidate parents (i.e. adult genets) using CERVUS version 3.0 [50] with maximum-likelihood algorithms [51]. The simulation parameters were as follows: 10,000 cycles, 306 candidate parents, 0.95 as the proportion of candidate parents sampled, 0.997 (calculated from the data) as the proportion of loci typed, 0.01 as the rate of typing errors, $95 \%$ for the strict confidence level and $80 \%$ for the relaxed confidence level. For the proportion of candidate parents sampled, we were confident that we sampled all extant candidate parents within the populations. However, we did not conduct a flowering census in 2005 (the year seeds were sampled), so it is possible that a few adult genets that had not identified as flowering genets in the censuses from 2002 to 2004 may have flowered in 2005. Therefore, we set this parameter at 0.95 . We allowed selfing in the parentage testing, because M. stellata is self-compatible, setting the selfing rate at 0.20 based on our previous data [52]. According to the assigned paternity data, we categorized the offspring as derived from selfing, outcrossing within the study area, and outcrossing with a paternal parent that was not present in the study area. We defined the selfing rate as the number of selfed offspring divided by the number of examined offspring from each genet.

\section{Factors influencing the female reproductive success and selfing rate}

To investigate the factors that influence the female reproductive success and selfing rate, we applied a GLM with a binomial error distribution and a logistic-link function using R 2.11.1 [53]. We defined genet size as the basal area $\left(\mathrm{cm}^{2}\right)$ of the largest stem of each adult genet at breast height $\left(\pi \times(\mathrm{DBH} \text { of the largest stem of genet } / 2)^{2}\right)$. As explanatory variables in the GLM, we chose maternal genet size (genet size of a focal maternal genet), local genet density (summed size of adult genets within a certain radius, $x$ in meters, of the focal maternal genet), population size (summed size of adult genets in the focal maternal genet's population) and neighbouring population size (sum of neighbouring population size within a $300 \mathrm{~m}$ radius from the focal maternal genet) as a indicator of population isolation. We have previously shown that the size of maternal genets affects their floral display size and thus attractiveness to pollinators $[39,40]$. Therefore, we used summed genet sizes to indicate the local genet density and population size, rather than numbers of adult genets, in order to evaluate effects of both the number and size of individual genets simultaneously. To determine the most appropriate radius for neighbouring genets, radii with $5 \mathrm{~m}$ increments from 5 to $50 \mathrm{~m}$ were tested in the GLMs. We set the upper radius at $50 \mathrm{~m}$ since most pollen flow occurs within $50 \mathrm{~m}$ in this species [38]. Neighboring populations were defined as the populations that including at least one individual within the radius $300 \mathrm{~m}$ from the focal maternal genet except for the focal maternal population. The radius for neighboring population was set as $300 \mathrm{~m}$ since it can cover the adjacent populations from each focal population. To select models for estimating parameters for the explanatory variables we calculated Akaike's Information Criterion (AIC) values [54]. Models with lower AIC values have higher likelihoods and smaller numbers of parameters than alternative models.

\section{Estimation of pollen dispersal parameters and factors affecting male reproductive success}

Pollen dispersal events identified by paternity analyses were used to estimate a pollen dispersal kernel characterizing pollen movements within our study area, in terms of an exponential power function [55]. Using this function, the probability of pollen dispersal $d$ over distance $r$ (m) was defined as:

$$
d=\frac{a^{2} b}{2 \pi \Gamma(2 / b)} \exp \left(-[a r]^{b}\right)
$$

where $\Gamma$ is the gamma function, and $a$ and $b$ are scale and shape parameters, respectively. The mean dispersal distance is expressed as $\Gamma(3 / b) / a \Gamma(2 / b)$ [56]. This function has been more frequently used than Weibull, geometric, Student's $t$ and other functions because various dispersal patterns can be expressed using solely the shape parameter of the exponential power function, such as an exponential distribution $(b=1)$, normal distribution $(b=2)$, fat-tailed $(b<1)$ or thin-tailed $(b>1)$, leptokurtic $(b<2)$ or platykurtic $(b>2)$ distributions [56].

We examined the male reproductive success based on the dispersal kernel. For maternal genet $i=\{1,2, \ldots$, $M\}$, the number of seeds $n_{i j}(i \neq j)$ sired by male genet $j=\{1,2, \ldots, N\}$ is assumed to follow a multinomial distribution with the probability $p_{i j}$ and sample size $\sum_{k=1(k \neq i)}^{N-1} n_{i k}$. The probability $p_{i j}(i \neq j)$ that male genet $j$ sired seeds of maternal genet $i$ was determined using parameters of pollen dispersal $a, b$ and male reproductive success $f_{i j}$ $(i \neq j)$ from male genet $j$ to maternal genet $i$ in the form:

$$
p_{i j}=\frac{f_{i j} \exp \left(-\left[a r_{i j}\right]^{b}\right)}{\sum_{k=1(k \neq i)}^{N-1} f_{i k} \exp \left(-\left[a r_{i k}\right]^{b}\right)},
$$

where $r_{i j}(i \neq j)$ is the distance $(\mathrm{m})$ between maternal genet $i$ and male genet $j$. Male reproductive success $f_{i j}$ was 
determined from the relative size $s_{i j}$ of male genet $j$ to maternal genet $i\left(s_{i j}=\right.$ genet size of $j$ / genet size of $i$, relative genet size), the relative size $t_{i j}$ of the population of male genet $j$ to the population of maternal genet $i\left(t_{i j}=\right.$ population size of genet $j$ / population size of genet $i$, relative population size) and the geographic separation $u_{i j}$ of populations of the maternal genet $i$ and male genet $j$ $\left(u_{i j}=0\right.$ when the maternal and male genets belonged to the same population, and $u_{i j}=1$ when they belonged to different populations, separation of population) in the form:

$$
f_{i j}=s_{i j}{ }^{a} t_{i j}^{\beta} \exp \left(\gamma \mu_{i j}\right),
$$

where $\alpha, \beta$ and $\gamma$ are parameters of $s_{i j}, t_{i j}$ and $u_{i j}$, respectively. The mating likelihood function for $M$ maternal genets and $N$ male genets was expressed as:

$$
L(n, r, s, t, u \mid a, b, \alpha, \beta, \gamma)=\prod_{i=1}^{M} \prod_{j=1}^{N-1} p_{i j}{ }^{{ }^{i j}} \text {. }
$$

The posterior probability distributions were derived from the likelihood and non-informative prior probability distributions (gamma distributions with mean 1 and variance 1,000 for $a$ and $b$, and normal distributions with mean 0 and variance 1,000 for $\alpha, \beta$ and $\gamma$ ).

Posterior distributions of the parameters were computed as conditional distributions that were updated based on the $n_{i j}, r_{i j}, s_{i j}, t_{i j}$, and $u_{i j}$ data. Initial values $(a=b=1$, $\alpha=\beta=\gamma=0$ ) were first defined and then updated, to fit the data relating to the probability $p_{i j}$ that male genet $j$ sired seeds of maternal genet $i$, in three chains of MCMC sampling implemented in JAGS software using the rjags package in R2.11.1 [57]. Each chain was run for 20,000 iterations with parameter values recorded every 20 iterations after a burn-in period of 2,000 iterations. MCMC convergence after all iterations in the three chains for the parameters was visualized by the coda package, and confirmed by $\mathrm{R}$-hat $<1.1$ using the function gelman.diag. The parameter estimates, the median and range between 2.5 and 97.5 percentiles, were obtained from the 2,700 MCMC samples.

\section{Results}

\section{Female reproductive success}

The mean seed production rate for each population ranged from $0.98 \%$ (population B) to $6.50 \%$ (population A) and was $4.00 \%$ for the six populations on average (Table 1 ). According to the AIC and $\triangle \mathrm{AIC}$ values, the model providing the best explanation for the variation in the seed production rate included four explanatory variables: maternal genet size, local genet density within a $50 \mathrm{~m}$ radius, population size and neighboring population size (Table 2). The estimated parameters of these variables were positive for population size and neighboring population size and negative for maternal genet size and local genet density (Table 3), indicating that female reproductive success increased as the population size and neighboring population size increased and as the maternal genet size and the local genet density decreased.

\section{Paternity assignment}

Pollen parents of all 493 offspring examined here were identified at the $95 \%$ confidence level, thus no offspring with a pollen parent outside the study area was found. Of the 493 offspring, 57 (11.56\%) were derived from selfing (Table 1), and pollen parents of 436 outcrossed progeny were assigned to 115 out of 306 candidates (37.58\%) within the study area.

\section{Selfing rate}

No selfing was detected for 30 genets, but the selfing rates of the other 22 ranged from 5.88 to $100.00 \%$ (Table 1 ). The model providing the lowest AIC value for the variations in the selfing rate included two explanatory variables (maternal genet size and local genet density within a 25 m radius) (Table 2). The estimated parameter for the local genet density was negative (Table 3 ), indicating that the selfing rates were higher for genets with lower densities of neighboring genets. The estimated parameter for the maternal genet size was positive, suggesting that larger genets have higher selfing rates.

\section{Pollen flow and male reproductive success}

Of the 436 outcrossed progeny, 30 originated from mating between genets in different populations (6.88\%), and 406 from mating between genets in the same populations (93.12\%) (Table 1, Additional file 1). Among pollen flow events detected between populations, the most frequent were from $\mathrm{T}$ to $\mathrm{Y}, \mathrm{A}$ to $\mathrm{T}$ and $\mathrm{Y}$ to $\mathrm{A}$ (nine, four and four mating events, respectively; Figure 1, Additional file 1). All six populations used in this analysis were connected by pollen flow, but the central three populations (A, T and $\mathrm{Y}$ ) were both donors and recipients of the observed pollen flow, while the peripheral populations were either donors (population B) or recipients (populations $\mathrm{C}$ and F) (Figure 1).

On the basis of the observed pollen flow pattern, posterior distributions of the two pollen dispersal parameters and three male reproductive success parameters were estimated from three converging MCMC sampling chains (R-hat < 1.1) (Table 4). Medians and 95\% ranges of the pollen dispersal scale and shape parameters, which were correlated (Figure 2a), were estimated, and a pollen dispersal curve with confidence levels was obtained from the estimates (Figure 2b). The curve was leptokurtic and fat-tailed ( $b=0.206$ ) (Table 4), and the mean dispersal distance was $602 \mathrm{~m}$, with a $95 \%$ range from 95 to $7,962 \mathrm{~m}$. Among the three male reproductive success parameters, the size of 
Table 2 The intercept and parameters included in the best and other models (according to Akaike's Information Criterion, AIC) explaining the female reproductive success and selfing rate of Magnolia stellata offspring

\begin{tabular}{|c|c|c|c|c|c|c|}
\hline \multirow{2}{*}{$\begin{array}{l}\text { Model } \\
\text { rank }\end{array}$} & \multicolumn{3}{|l|}{ Ovule survival rate } & \multicolumn{3}{|l|}{ Selfing rate } \\
\hline & Model & AIC & $\triangle \mathrm{AIC}$ & Model & AIC & $\triangle \mathrm{AIC}$ \\
\hline 1 & $\begin{array}{c}\text { c, maternal genet size, local density }(50 \mathrm{~m}) \text {, population size, } \\
\text { neighboring population size }\end{array}$ & 15766.1 & 0.0 & c, maternal genet size, local density $(25 \mathrm{~m})$ & 299.5 & 0.0 \\
\hline 2 & $\begin{array}{c}\text { c, maternal genet size, local density }(50 \mathrm{~m}) \text {, neighboring } \\
\text { population size }\end{array}$ & 15776.5 & 10.4 & $\begin{array}{l}\text { c, maternal genet size, local density }(25 \mathrm{~m}) \text {, } \\
\text { population size }\end{array}$ & 300.8 & 1.3 \\
\hline 3 & $\begin{array}{c}\text { c, maternal genet size, local density }(40 \mathrm{~m}) \text {, population size, } \\
\text { neighboring population size }\end{array}$ & 15791.8 & 25.7 & $\begin{array}{c}\text { c, maternal genet size, local density }(25 \mathrm{~m}) \text {, } \\
\text { neighboring population size }\end{array}$ & 301.3 & 1.8 \\
\hline 4 & $\begin{array}{c}\text { c, maternal genet size, local density }(45 \mathrm{~m}) \text {, population size, } \\
\text { neighboring population size }\end{array}$ & 15799.9 & 33.8 & c, local density $(25 \mathrm{~m})$ & 301.7 & 2.2 \\
\hline 5 & c, local density $(40 \mathrm{~m})$, pulation size, neighboring population size & 15805.4 & 39.3 & c, maternal genet size, local density $(30 \mathrm{~m})$ & 301.8 & 2.3 \\
\hline
\end{tabular}

Abbreviations: $\triangle \mathrm{AIC}$, the difference in AIC between the model considered and the most parsimonious model; $c$, intercept. Numbers in the parentheses after local density are the radius used to calculate the local genet density.

paternal genets relative to maternal genets had a positive effect $(\alpha=0.711)$, whereas both the population size of paternal genets relative to that of maternal genets $(\beta=-0.302)$ and geographical separation of populations $(\gamma=-0.575)$ had negative effects (Table 4). The relative genet size and separation of populations had substantial effects, since $95 \%$ ranges of these parameter estimates did not include 0 , while the relative population size did not have a clear effect. Hence, the estimated parameters indicated that male reproductive success in mating between populations was lower than that within populations, and positively associated with the size of paternal genets, but negatively associated with the size of the genets' populations.

\section{Discussion}

Female reproductive success and selfing rate

Of the germinating seeds included in this study, $11.56 \%$ originated from selfing, in accordance with the known self-compatibility and mixed mating system of $M$. stellata [34] and congeneric species $M$. obovata [58,59]. Habitat fragmentation tends to decrease reproductive success less in self-compatible species than in self-incompatible species because selfing can compensate for reductions in seed production due to pollen limitation in fragmented populations [7]. However, despite the selfing potential, pollen limitations of seed production have been detected in fragmented M. stellata populations [33,60]. Hirayama et al. [33] found that manual cross-pollination results in the highest seed production rate, natural pollination the lowest, and manual self-pollination intermediate levels in fragmented populations of the species, suggesting that pollen shortage causes ovule mortality and selfing causes embryo mortality. Therefore, if outcross and/or self pollen is limited in the studied populations, pollen limitation is likely to impair their seed production and/or outcrossing opportunities.

Seed production rates increased as the population size and neighboring population size increased (Table 3). The size of focal and neighboring populations, which were indicated by the summed size of adult genets, would be positively correlated with the floral resources in the focal and surrounding populations. The rich floral resources could increase the pollinator abundance in the focal populations, leading to higher seed production rates. In the best model, the coefficient for population size was about 4.4 times higher than that of neighboring population size (Table 3), which suggests that pollinators maintained in populations are mainly dependent on floral resources in

Table 3 Fixed explanatory variables of the generalized linear models that best explained female reproductive success, and the selfing rate of Magnolia stellata populations, selected according to Akaike's information Criterion (AIC)

\begin{tabular}{|c|c|c|c|c|}
\hline Response variables & Explanatory variables & Coefficients & S.E. & $p$ value \\
\hline \multirow[t]{5}{*}{ Ovule survival rate } & c & -4.20200 & 0.05343 & $<0.001$ \\
\hline & maternal genet size & -0.00256 & 0.00074 & $<0.001$ \\
\hline & local density $(50 \mathrm{~m})$ & -0.00056 & 0.00004 & $<0.001$ \\
\hline & population size & 0.00055 & 0.00003 & $<0.001$ \\
\hline & neighboring population size & 0.00013 & 0.00001 & $<0.001$ \\
\hline \multirow[t]{3}{*}{ Selfing rate } & c & -1.21029 & 0.47454 & $<0.05$ \\
\hline & maternal genet size & 0.12485 & 0.06044 & $<0.05$ \\
\hline & local density $(25 \mathrm{~m})$ & -0.00534 & 0.00105 & $<0.001$ \\
\hline
\end{tabular}


the focal populations and subsidized by those in surrounding populations. In the study site, most populations covered several hundred meters along the valleys, corresponding to the mean pollen dispersal distance $(602 \mathrm{~m})$. Pollination events between populations were rare $(6.09 \%)$ and increases in the geographical separation of the populations significantly reduced siring success (Table 4), suggesting that most movements of pollinators occur within the populations. Thus, the populations are likely to harbor their own pollinators, partially isolating them from the other populations.

On the other hand, the local genet density had negative effects on the seed production rate, and there are two possible explanations (Table 3). First, the seed production may be reduced by the inbreeding depression due to biparental inbreeding, i.e. mating between relatives. If genetic spatial autocorrelation exists in populations, biparental inbreeding would occur, especially in the area where local genet density is high, since the pollen dispersal is limited in M. stellata as shown in this study. Under such circumstances, the opportunity to mate with relatives would increase and thus decrease the seed production rate due to inbreeding depression. However, our previous study did not detect significant spatial autocorrelation among adult genets [45], and therefore increased biparental inbreeding with increasing local genet density is not supported. Second, local competition for pollinators among neighboring plants could explain the negative effect of local density on seed production. Although it is unusual for local plant density to be negatively correlated with female reproductive success $[61,62]$, there are a few known examples of large plant aggregations increasing competition for pollinators $[15,63]$. In spite of the occurrence of pollen dispersal over several hundred meters, the leptokurtic dispersal curve indicates that most pollination events occurred within about $50 \mathrm{~m}$, corresponding to the scale of the local genet density (Figure 2). Thus, pollinator movements seem to be restricted to the local range, and limited availability of pollinators within the range is likely to result in the competition among the local genets.

In a previous analysis of hierarchical variation in the proportion of M. stellata seeds derived from selfing found, the selfing rate did not significantly differ among populations, but did vary among genets within populations [34].

Table 4 Medians and $95 \%$ confidence intervals of parameters estimated by MCMC sampling

\begin{tabular}{lccc}
\hline & Parameter & Median & $\mathbf{( 9 5 \% ~ C I ) ~}$ \\
\hline$a$ & scale parameter & 239.709 & $(18.107,1522.016)$ \\
$b$ & shape parameter & 0.206 & $(0.182,0.257)$ \\
$a$ & relative genet size & 0.711 & $(0.593,0.832)$ \\
$\beta$ & relative population size & -0.302 & $(-0.752,0.156)$ \\
$\gamma$ & separation of population & -0.575 & $(-1.105,-0.021)$ \\
\hline
\end{tabular}

Notwithstanding large variation in the selfing rate among genets, in the present study it was negatively correlated with local genet density. In accordance with our findings, there are tendencies for the selfing rate of various species to decrease with increases in both the local plant density and population size [2,64-66]. Van Treuren et al. [67], in particular, found that selfing in Salvia pratensis was promoted by low plant density, but there was no correlation between the selfing rate and population size. A low density of neighboring genets is likely to result in outcross pollen limitation and a high frequency of selfing, which can partly compensate for reductions in seed production.

The maternal genet size had negative effects on the seed production rates and positive effects on the selfing rate. This result conflicts with the expectation that the large plants have ample resources to produce large number of seeds and have large floral display to increase pollinator
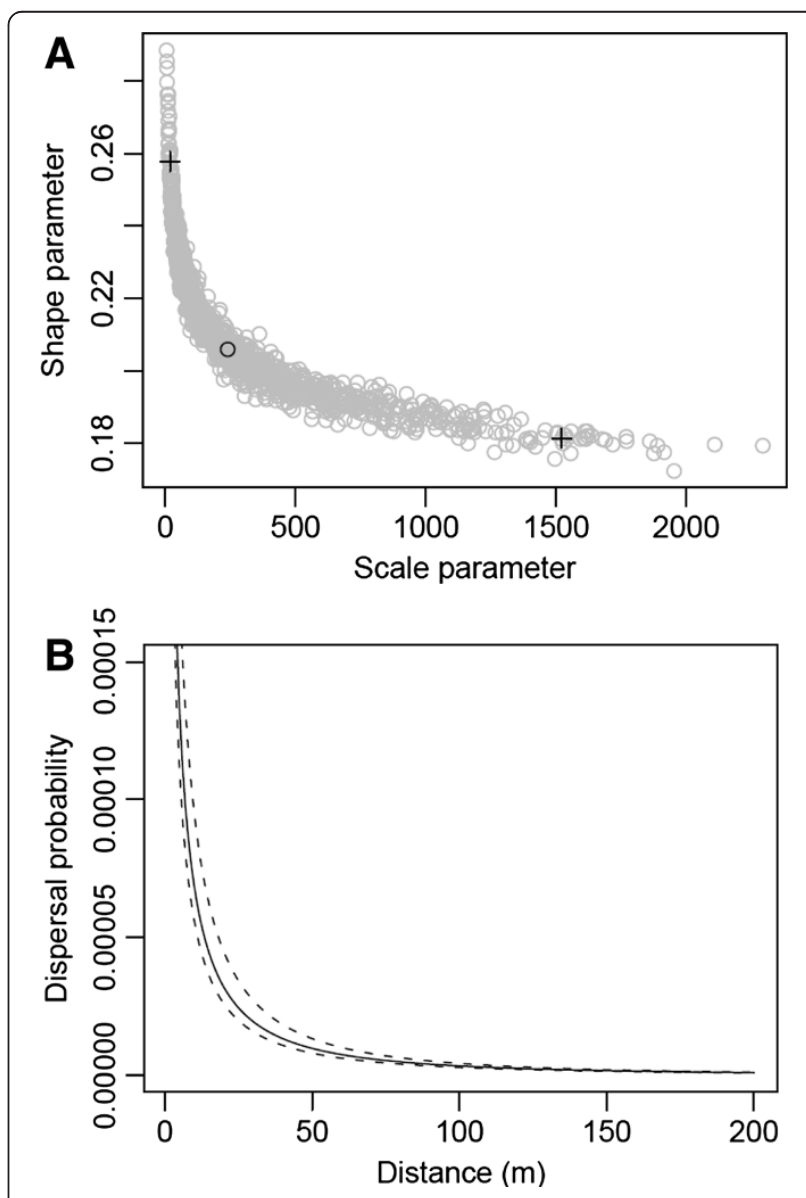

Figure 2 A) Distributions of scale (a) and shape parameters (b) obtained by MCMC sampling. The black circle indicates the median of the two parameters and plus signs indicate upper and lower limits of their $95 \%$ credible intervals. B) Estimated pollen dispersal curve (solid line) derived from modeling pollen dispersal with male reproductive success, when medians of the scale and shape parameters are applied, and upper and lower limits of the 95\% credible interval obtained by MCMC sampling (dashed lines). 
visitation, and thus have high seed production rate [68,69] and high outcrossing rate $[70,71]$. The result, however, suggests that larger genets with more flowers are frequently received geitonogamous pollination, and thus have higher selfing rate and reduces seed production [72,73]. Geitonogamous selfing is likely in $M$. stellata because its femalestage flowers lack rewards but morphologically mimicking male-stage flowers that produce pollinator-attracting pollen [42], and asynchronously opening within genets [74]. Selfpollination rate would increase along with the increase of maternal genet size, and some self-fertilized embryo would be aborted as Hirayama et al. [33] reported that 36 to $38 \%$ of the embryo is aborted by the self-pollination in $M$. stellata. The partial abortion decreases the seed production rates, and development of remaining self-fertilized embryos would increase the selfing rate.

In previous research [39], however, we found that the maternal genet size and the floral display size of neighboring genets were both positively correlated with their female reproductive success in population $\mathrm{Y}$. This result is inconsistent with our present study. Thus, the effects of the maternal genet size and local genet density on female reproductive success seem to vary among populations and among years, and further research is needed to elucidate more fully the relationships among the variables and to identify more clearly the influential factors.

\section{Pollen flow and male reproductive success}

Owing to the low value of cryptic gene flow (0.025 = $\left.1-0.99992^{306}\right)$, the incorrect assignment of genets within sampled candidates as pollen donors, pollen parents of nearly all examined offspring were identified amongst adult genets within the study area. The estimated shape parameter $(b=0.21)$ of the pollen dispersal kernel is smaller than previously reported values for other insect-pollinated tree species $[21,32,55,56,75-78]$. These comparisons suggest that the dispersal kernel of $M$. stellata pollen is more fat-tailed than usual, indicating extreme variation in the dispersal distance, with frequent short and rare long dispersal [56]. Among various insect visitors of $M$. obovata flowers, flower beetles (Scarabaeidae) carry more outcross pollen, and hence pollen with higher genetic diversity, than bumblebees and small beetles [79]. Thus, some groups of flower beetles may carry pollen over during subsequent visits among flowering genets. The main pollinators of $M$. stellata are also reportedly beetles, of the Staphylinidae [40], but their pollination efficiency has not been evaluated. These findings suggest that the beetle pollinators of M. stellata may occasionally disperse pollen over long distances, thus explaining the observed fat-tailed dispersal pattern.

Despite the potential for pollen dispersal over long distance, male reproductive success in mating between populations was estimated to be about half $\left(\exp \left(\gamma u_{\mathrm{ij}}\right)=e^{-0.575}=\right.$ 0.563 ) that of mating within populations. This suggests that the ridges between the $M$. stellata populations are topographical barriers that impede pollen flow, possibly because different environmental conditions on the ridges hinder movements of beetle pollinators between the valleys.

The frequency of pollen-mediated gene immigration often increases as population size decreases [27], and small populations of tree species reportedly receive immigrating pollen more frequently from larger populations than vice versa [80]. These patterns seem to result from the greater abundance of pollen dispersed from large populations, regardless of the siring success of individual genets. In this study, however, the male reproductive success of individual genets tended to be higher in small populations than in large populations. Movement patterns of pollinators expected from foraging theory are probably responsible for this finding [81]. In large populations with many flowering genets, pollinators are likely to forage sequentially on abundant resources within the populations and rarely leave them. In contrast, pollinators may stay for short times within small populations and frequently leave them. These foraging patterns could enhance the probability of pollen transfer between populations from genets in small populations, in accordance with observations of increased average pollination distances in fragmented populations of animalpollinated trees $[27,82]$.

The estimated parameter for the effect of genet size on male reproductive success was positive, suggesting that large genets tend to have higher male reproductive success. Our previous study also indicated that larger genets sired more seedlings that had established in the study area [52]. Large genets tended to have many flowers [39], and thus abundant rewards that should attract pollinators and increase male reproductive success in spite of pollen discounting due to geitonogamous selfing.

\section{Conclusions}

The findings of this study suggest that population structure affects mating patterns and reproductive success in $M$. stellata. Population fragmentation is likely to reduce its female and male reproductive success due to associated reductions in population sizes and increases in the geographic separation of the populations.

In spite of the potential for long-distance pollen dispersal, mating between populations was rare. Genets in larger populations tend to have higher female reproductive success, but may have lower male reproductive success. Larger genets tend to have lower seed production rates and outcrossing rates, due to geitonogamy, but higher male reproductive success. In attempts to conserve rare species, only large populations with large individuals are often selected as conservation targets. However, our study suggests that individual populations may have different, size-dependent roles. In order to conserve M. stellata populations, not only large populations but also small 
populations should be considered to maintain seed reproduction and gene flow between local populations, respectively.

\section{Additional file}

Additional file 1: Population size and number of offspring sired by each of the examined Magnolia stellata populations.

\section{Competing interests}

The authors declare that they have no competing interests.

\section{Authors' contributions}

SS participated in the design of the study, sample collection, genetic analyses and drafted the manuscript. TN contributed to the statistical analyses and interpretation of the results. NT collaborated in the study design and sample collection. All authors read and approved the final manuscript.

\section{Acknowledgements}

The authors thank members of the laboratory of the Forest Ecology and Physiology Department of Nagoya University for their assistance with fieldwork. We are particularly grateful to S. Yamamoto, I. Tamaki, M. Matsushita and S. Shota for their support and valuable advice. We also thank the Aichi Kaisho Forest Center for allowing this study, which was supported by funds from JSPS Research Fellowships for Young Scientists (1707746, 2110333), Grants-in-Aid for Scientific Research $(14206017,16380100)$ from the Japanese Society for the Promotion of Science and a grant from the Ministry of the Environment Government of Japan. We thank anonymous reviewers for improving an earlier draft of this paper.

\section{Author details}

'Department of Forest Genetics, Forestry and Forest Products Research Institute, Tsukuba, Ibaraki 305-8687, Japan. '2Laboratory of Forest Ecology and Physiology, Graduate School of Bioagricultural Sciences, Nagoya University, Nagoya 464-8601, Japan.

Received: 1 August 2012 Accepted: 7 March 2013

Published: 22 March 2013

\section{References}

1. Aguilar R, Ashworth L, Galetto L, Aizen MA: Plant reproductive susceptibility to habitat fragmentation: review and synthesis through a meta-analysis. Ecol Lett 2006, 9(8):968-980.

2. Eckert CG, Kalisz S, Geber MA, Sargent R, Elle E, Cheptou P-O, Goodwillie C, Johnston MO, Kelly JK, Moeller DA, et al: Plant mating systems in a changing world. Trends Ecol Evol 2010, 25(1):35-43.

3. González-Varo JP, Albaladejo RG, Aparicio A, Arroyo J: Linking genetic diversity, mating patterns and progeny performance in fragmented populations of a Mediterranean shrub. J Appl Ecol 2010, 47(6):1242-1252.

4. Barrett SCH, Kohn JR: Genetic and evolutionary consequences of small population size in plants: implications for conservation. In Genetics and conservation of rare plants. Edited by Falk DA, Holsinger KE. New York, USA Oxford University Press; 1991:3-30.

5. Ellstrand NC, Elam DR: Population genetic consequences of small population size: implications for plant conservation. Annu Rev Ecol Syst 1993, 24:217-242.

6. Hobbs RJ, Yates CJ: Turner Review No. 7. Impacts of ecosystem fragmentation on plant populations: generalising the idiosyncratic. Aust J Bot 2003, 51(5):471-488.

7. Aguilar R, Quesada M, Ashworth L, Herrerias-Diego Y, Lobo J: Genetic consequences of habitat fragmentation in plant populations: susceptible signals in plant traits and methodological approaches. Mol Ecol 2008 , 17(24):5177-5188.

8. Hamrick JL: Response of forest trees to global environmental changes. Forest Ecol Manag 2004, 197(1-3):323-335

9. Kramer AT, Ison JL, Ashley MV, Howe HF: The paradox of forest fragmentation genetics. Conserv Biol 2008, 22(4):878-885.
10. Vranckx G, Jacquemyn H, Muys B, Honnay O: Meta-analysis of susceptibility of woody plants to loss of genetic diversity through habitat fragmentation. Conserv Biol 2011, 26(2):228-237.

11. Mustajärvi K, Siikamäki $P$, Rytkönen S, Lammi A: Consequences of plant population size and density for plant-pollinator interactions and plant performance. J Ecol 2001, 89(1):80-87.

12. Sih A, Baltus MS: Patch size, pollinator behavior, and pollinator limitation in catnip. Ecology 1987, 68:1679-1690.

13. Ghazoul J: Pollen and seed dispersal among dispersed plants. Biol Rev 2005, 80(3):413-443

14. Kato E, Hiura T: Fruit set in Styrax obassia (Styracaceae): The effect of light availability, display size, and local floral density. Am J Bot 1999, 86(4):495-501

15. Ward M, Johnson S, Zalucki M: When bigger is not better: intraspecific competition for pollination increases with population size in invasive milkweeds. Oecologia 2012. doi:10.1007/s00442-012-2463-0.

16. Coates DJ, Sampson JF, Yates CJ: Plant mating systems and assessing population persistence in fragmented landscapes. Aust J Bot 2007 55(3):239-249.

17. Charpentier A: Consequences of clonal growth for plant mating. Evol Ecol 2001, 15(4-6):521-530

18. Fuchs EJ, Lobo JA, Quesada M: Effects of forest fragmentation and flowering phenology on the reproductive success and mating patterns of the tropical dry forest tree Pachira quinata. Conserv Biol 2003, 17(1):149-157.

19. Husband BC, Schemske DW: Evolution of the magnitude and timing of inbreeding depression in plants. Evolution 1996, 50(1):54-70.

20. Angeloni F, Ouborg N, Leimu R: Meta-analysis on the association of population size and life history with inbreeding depression in plants. Biol Conserv 2011, 144(1):35-43.

21. Dick CW, Etchelecu G, Austerlitz F: Pollen dispersal of tropical trees (Dinizia excelsa: Fabaceae) by native insects and African honeybees in pristine and fragmented Amazonian rainforest. Mol Ecol 2003, 12(3):753-764

22. Bacles CFE, Ennos RA: Paternity analysis of pollen-mediated gene flow for Fraxinus excelsior L. in a chronically fragmented landscape. Heredity 2008, 101(4):368-380.

23. White GM, Boshier DH, Powell W: Increased pollen flow counteracts fragmentation in a tropical dry forest: an example from Swietenia humilis Zuccarini. Proc Natl Acad Sci U S A 2002, 99(4):2038-2042.

24. Townsend PA, Levey DJ: An experimental test of whether habitat corridors affect pollen transfer. Ecology 2005, 86(2):466-475.

25. Ashley MV: Plant parentage, pollination, and dispersal: how DNA microsatellites have altered the landscape. Cr Rev Plant Sci 2010, 29(3):148-161.

26. Hoebee SE, Arnold U, Duggelin C, Gugerli F, Brodbeck S, Rotach P, Holderegger R: Mating patterns and contemporary gene flow by pollen in a large continuous and a small isolated population of the scattered forest tree Sorbus torminalis. Heredity 2007, 99(1):47-55.

27. Sork VL, Smouse PE: Genetic analysis of landscape connectivity in tree populations. Landscape Ecol 2006, 21(6):821-836.

28. Lander TA, Boshier DH, Harris SA: Fragmented but not isolated: Contribution of single trees, small patches and long-distance pollen flow to genetic connectivity for Gomortega keule, an endangered Chilean tree. Biol Conserv 2010, 143(11):2583-2590

29. Adams WT, Birkes DS, Fineschi S: Estimating mating patterns in forest tree populations. In Biochemical markers in the population genetics of forest trees. Edited by Malvetti ME, Cannata F, Hattemer HH. Hague Netherlands: SPB Academic; 1991:157-172

30. Adams WT, Birkes DS: Mating patterns in seed orchards. In Proceedings of the 20th Southern Forest Tree Improvement Conference. Charleston, SC, USA; 1989:75-86

31. Burczyk J, Adams WT, Moran GF, Griffin AR: Complex patterns of mating revealed in a Eucalyptus regnans seed orchard using allozyme markers and the neighbourhood model. Mol Ecol 2002, 11:2379-2391.

32. Klein E, Desassis N, Oddou-Muratorio S: Pollen flow in the wildservice tree, Sorbus torminalis (L.) Crantz. IV. Whole interindividual variance of male fecundity estimated jointly with the dispersal kernel. Mol Ecol 2008, 17(14):3323-3336.

33. Hirayama K, Ishida K, Setsuko S, Tomaru N: Reduced seed production, inbreeding, and pollen shortage in a small population of a threatened tree, Magnolia stellata. Biol Conserv 2007, 136:315-323. 
34. Tamaki I, Ishida K, Setsuko S, Tomaru N: Interpopulation variation in mating system and late-stage inbreeding depression in Magnolia stellata. Mol Ecol 2009, 18:2365-2374.

35. Nooteboom HP: Proposals to reject Magnolia tomentosa (Thymelaeaceae) and conserve Magnolia kobus (Magnoliaceae) with a conserved type. Taxon 1994, 43(3):467-468.

36. Ueda K: A nomenclatural revision of the Japanese Magnolia species (Magnoliaceae), together with two long-cultivated Chinese species. II. M. tomentosa and M. praecocissima. Taxon 1986, 35:344-347.

37. Ministry of the Environment Government of Japan: Red list (Plant I) Vascular plants. http://www.env.go.jp/press/file_view.php? serial=9947\&hou_id $=8648$.

38. Setsuko S, Ishida K, Ueno S, Tsumura Y, Tomaru N: Population differentiation and gene flow within a metapopulation of a threatened tree, Magnolia stellata (Magnoliaceae). Am J Bot 2007, 94(1):128-136.

39. Setsuko S, Tamaki I, Ishida K, Tomaru N: Relationships between flowering phenology and female reproductive success in the Japanese tree species Magnolia stellata. Botany 2008, 86:248-258.

40. Setsuko S, Nagamitsu T, Ishida K, Tomaru N: Relationships between flowervisiting insects and female reproductive success in Magnolia stellata (in Japanese). Chubu For Res 2012, 60:37-42.

41. Ishida K: Beetle pollination of Magnolia praecocissima var. borealis. Plant Species Biol 1996, 11:199-206.

42. Kikuzawa K, Mizui N: Flowering and fruiting phenology of Magnolia hypoleuca. Plant Species Biol 1990, 5:255-261.

43. Bernhardt $P$, Thien LB: Self-isolation and insect pollination in the primitive angiosperms: new evaluations of older hypotheses. Plant Syst Eol 1987, 156:159-176.

44. Thien LB: Floral biology of Magnolia. Am J Bot 1974, 61(10):1037-1045.

45. Setsuko S, Ishida K, Tomaru N: Size distribution and genetic structure in relation to clonal growth within a population of Magnolia tomentosa Thunb. (Magnoliaceae). Mol Ecol 2004, 13:2645-2653.

46. Tamaki I, Hoshino D, Setsuko S, Tomaru N, Yamamoto S: Population structure of woody species in the Kaisho Forest. Chubu For Res 2005, 53:45-48 (in Japanese)

47. Murray MG, Thompson WF: Rapid isolation of high molecular weight plant DNA. Nucleic Acids Res 1980, 8:4321-4325.

48. Isagi $Y$, Kanazashi T, Suzuki W, Tanaka H, Abe T: Polymorphic microsatellite DNA markers for Magnolia obovata Thunb. and their utility in related species. Mol Ecol 1999, 8:698-700.

49. Setsuko S, Ueno S, Tsumura Y, Tomaru N: Development of microsatellite markers in Magnolia stellata (Magnoliaceae), a threatened Japanese tree. Conserv Genet 2005, 6:317-320.

50. Kalinowski ST, Taper ML, Marshall TC: Revising how the computer program cervus accommodates genotyping error increases success in paternity assignment. Mol Ecol 2007, 16(5):1099-1106

51. Meagher TR: Analysis of paternity within a natural population of Chamaelirium luteum. 1. Identification of most-likely male parents. Am Nat 1986, 128:199-215

52. Setsuko S, Tomaru N: The effects of plant size and light availability on male and female reproductive success and functional gender in a hermaphrodite tree species, Magnolia stellata. Botany 2011, 89(9):593-604.

53. R Development Core Team: R: a Language and Environment for Statistical Computing. www.r-project.org/.

54. Akaike $\mathrm{H}$ : Information theory and an extension of the maximum likelihood principle. In Proceedings of 2nd International Symposium on Information Theory. Budapest: Springer Verlag: 1973:267-281.

55. Oddou-Muratorio S, Klein EK, Austerlitz F: Pollen flow in the wildservice tree, Sorbus torminalis (L .) Crantz. II. Pollen dispersal and heterogeneity in mating success inferred from parent-offspring analysis. Mol Ecol 2005 14(14):4441-4452

56. Austerlitz F, Dick CW, Dutech C, Klein EK, Oddou-Muratorio S, Smouse PE, Sork VL: Using genetic markers to estimate the pollen dispersal curve. Mol Ecol 2004, 13(4):937-954.

57. Plummer M: JAGS: A program for analysis of Bayesian graphical models using Gibbs sampling. In Proceedings of the 3rd International Workshop on Distributed Statistical Computing. Vienna, Austria: Citeseer; 2003:20-22.

58. Isagi Y, Kanazashi T, Suzuki W, Tanaka H, Abe T: Highly variable pollination patterns in Magnolia obovata revealed by microsatellite paternity analysis. Int J Plant Sci 2004, 165(6):1047-1053.
59. Isagi Y, Tateno R, Matsuki Y, Hirao A, Watanabe S, Shibata M: Genetic and reproductive consequences of forest fragmentation for populations of Magnolia obovata. Ecol Res 2007, 22(3):382-389.

60. Hirayama K, Ishida K, Tomaru N: Effects of pollen shortage and selfpollination on seed production of an endangered tree, Magnolia stellata. Ann Bot-London 2005, 95:1009-1015.

61. Jones FA, Comita LS: Density-dependent pre-dispersal seed predation and fruit set in a tropical tree. Oikos 2010, 143(11):2583-2590.

62. Jones FA, Comita LS: Neighbourhood density and genetic relatedness interact to determine fruit set and abortion rates in a continuous tropical tree population. Proc R Soc Lond B Biol Sci 2008, 275(1652):2759.

63. Spigler RB, Chang S-M: Pollen limitation and reproduction varies with population size in experimental populations of Sabatia angularis (Gentianaceae). Botany 2009, 87(3):330-338

64. Farris MA, Mitton JB: Population density, outcrossing rate, and heterozygote superiority in ponderosa pine. Evolution 1984, 38(5):1151-1154.

65. Murawski D, Hamrick J: The effect of the density of flowering individuals on the mating systems of nine tropical tree species. Heredity 1991 , 67(2):167-174

66. Wolff $K$, Friso B, Damme JMM: Outcrossing rates and male sterility in natural populations of Plantago coronopus. Theor Appl Genet 1988, 76(2):190-196

67. Van Treuren R, Bijlsma R, Ouborg N, Van Delden W: The effects of population size and plant density on outcrossing rates in locally endangered Salvia pratensis. Evolution 1993, 47:1094-1104.

68. Ollerton J, Lack A: Relationships between flowering phenology, plant size and reproductive success in shape Lotus corniculatus (Fabaceae). Plant Ecol 1998, 139:35-47.

69. McIntosh ME: Flowering phenology and reproductive output in two sister species of Ferocactus (Cactaceae). Plant Ecol 2002, 159:1-13.

70. Mitchell RJ: Effects of floral traits, pollinator visitation, and plant size on Ipomopsis aggregata fruit production. Am Nat 1994, 143:870-889.

71. Klinkhamer PG, de Jong TJ, de Bruyn G-J: Plant size and pollinator visitation in Cynoglossum officinale. Oikos 1989, 54:201-204.

72. de Jong TJ, Waser NM, Price MV, Ring RM: Plant size, geitonogamy and seed set in Ipomopsis aggregata. Oecologia 1992, 89:310-315.

73. de Jong TJ, Waser NM, Klinkhamer PGL: Geitonogamy: The neglected side of selfing. Trends Ecol Evol 1993, 8(9):321-325.

74. Ishida $\mathrm{K}$, Yoshimaru $\mathrm{H}$, Ito $\mathrm{H}$ : Effects of geitonogamy on the seed set of Magnolia obovata Thunb. (Magnoliaceae). Int J Plant Sci 2003, 164(5):729-735.

75. Byrne M, Elliott CP, Yates CJ, Coates DJ: Maintenance of high pollen dispersal in Eucalyptus wandoo, a dominant tree of the fragmented agricultural region in Western Australia. Conserv Genet 2008, 9(1):97-105.

76. Hardy O, González-Martínez S, Fréville H, Boquien G, Mignot A, Colas B, Olivieri I: Fine-scale genetic structure and gene dispersal in Centaurea corymbosa (Asteraceae) I. Pattern of pollen dispersal. J Evolution Biol 2004, 17(4):795-806

77. Mimura M, Barbor RC, Potts BM, Vaillancourt RE, Watanabe KN: Comparison of contemporary mating patterns in continuous and fragmented Eucalyptus globulus native forests. Mol Ecol 2009, 18(20):4180-4192.

78. Oddou-Muratorio S, Klein EK: Comparing direct vs. indirect estimates of gene flow within a population of a scattered tree species. Mol Ecol 2008, 17(11):2743-2754

79. Matsuki Y, Tateno R, Shibata M, Isagi Y: Pollination efficiencies of flowervisiting insects as determined by direct genetic analysis of pollen origin. Am J Bot 2008, 95(8):925-930.

80. Bittencourt JVM, Sebbenn AM: Patterns of pollen and seed dispersal in a small, fragmented population of the wind-pollinated tree Araucaria angustifolia in southern Brazil. Heredity 2007, 99(6):580-591.

81. Pyke GH: Optimal foraging theory: a critical review. Annu Rev Ecol Syst 1984, 15:523-575.

82. Lowe AJ, Boshier D, Ward M, Bacles C, Navarro C: Genetic resource impacts of habitat loss and degradation; reconciling empirical evidence and predicted theory for neotropical trees. Heredity 2005, 95(4):255-273.

doi:10.1186/1472-6785-13-10

Cite this article as: Setsuko et al:: Pollen flow and effects of population structure on selfing rates and female and male reproductive success in fragmented Magnolia stellata populations. BMC Ecology 2013 13:10. 